\section{Educação
Por Escrito}

ARTIGO

\section{Editora}

Maria Inês Côrte Vitoria

PUCRS, RS, Brasil

\section{Editora Colaboradora}

Pricila Kohls dos Santos

PUCRS, RS, Brasil

\section{Equipe Editorial}

Carla Spagnolo

PUCRS, Brasil

Rosa Maria Rigo

PUCRS, Brasil

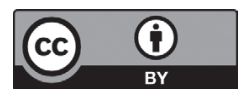

Este artigo está licenciado sob forma de uma licença Creative Commons Atribuiçăo 4.0 Internacional, que permite uso irrestrito, distribuiçáo e reprodução seja corretamente citada http://creativecommons.org/licenses/by/4.o/deed.pt_BB

\title{
A disciplina de Psicologia no Ensino Médio: revisitando as práticas dos professores da rede pública do Estado de São Paulo
}

\author{
The Psychology discipline in high school: revisiting the practices \\ of the teachers of the public network of the State of São Paulo
}

Lineu Norio Kohatsu ${ }^{1}$ Lucas Antunes Machado²

\section{RESUMO}

Este artigo tem por objetivo apresentar e discutir os dados obtidos junto aos professores de Psicologia sobre suas práticas no ensino médio da rede pública do Estado de São Paulo. Participaram da pesquisa 20 professores de Psicologia, concursados e efetivos, de escolas públicas pertencentes a Diretorias de Ensino da Capital, da região metropolitana e do interior do Estado de São Paulo. Os dados coletados por meio de um questionário auto-aplicável mostraram que um dos principais objetivos do ensino de Psicologia era a formação crítica dos alunos. Em relação ao conteúdo programático, foram mencionadas algumas teorias psicológicas, mas muitos professores citaram principalmente o trabalho com temas do cotidiano dos alunos. Quanto à metodologia de ensino, foram citadas aulas expositivas dialogadas combinadas com atividades diversas como leitura de textos, seminários, debates com a utilização de diversos recursos como música, filmes etc. que visavam à realização de aulas participativas e aprendizagem significativa dos alunos. A avaliação combinava diversos instrumentos e procedimentos, realizados individualmente ou em grupo. Pelo destaque dado pelos professores ao trabalho com temas, buscou-se retomar, ainda que brevemente, algumas propostas pedagógicas que historicamente se apresentaram como alternativas à educação tradicional. Por fim, considera-se que as discussões sobre o ensino de Psicologia no nível médio remetem às reflexões mais gerais sobre o currículo e a formação dos jovens das escolas públicas, revelando as contradições e as disputas que são travadas historicamente na educação.

Palavras-chave: Ensino de Psicologia; Ensino Médio; Escola pública; Licenciatura.

\footnotetext{
Doutor em Psicologia Escolar e do Desenvolvimento Humano pela USP. Professor do PPG em Psicologia Escolar e do Desenvolvimento Humano do Instituto de Psicologia da USP.

2 Graduando em Psicologia na Escola de Humanidade da PUCRS. Professor de Psicologia na rede pública do Estado do Rio
} Grande do Sul. Integrante do Grupos de Pesquisa: Teorias e Práticas na Formação de Professores. 


\section{ABSTRACT}

This article aims to present and discuss the data obtained from teachers of Psychology about their practices in public high school of the State of São Paulo. 20 teachers of Psychology participated in the research, insolvent and effective, from public schools that belong to Teaching Directories of the Capital, of the metropolitan region and in the countryside of the State of São Paulo. The data collected through a self-administered questionnaire showed that one of the main objectives of the teaching of Psychology was the critical formation of the students. In relation to the programmatic content, some psychological theories were mentioned, but many teachers cited mainly the work with subjects of the students' daily life. As for the methodology, there were lecture sessions combined with various activities such as reading texts, seminars, debates using various resources such as music, films, etc. which aimed at the accomplishment of participatory classes and significant learning of the students. The evaluation combined several instruments and procedures, either individually or in groups. Due to the emphasis given by teachers to the work with themes, it was sought to resume, albeit briefly, some pedagogical proposals that historically presented themselves as alternatives to traditional formation. Finally, it is considered that the discussions about the teaching of Psychology at high school level refer to more general reflections on the curriculum and the formation of the young people of the public schools, revealing the contradictions and the disputes that are fought historically in education.

Keywords: Psychology Teaching; High School; Public school; Teaching degree.

\section{Introdução}

_ ste artigo tem por objetivo apresentar e discutir os dados obtidos junto aos professores de Psicologia da rede $\checkmark$ pública do Estado de São Paulo e suas práticas no ensino médio.

Os resultados aqui apresentados fazem parte da pesquisa Concepções e práticas de professores efetivos de Psicologia do ensino médio do Estado de São Paulo ${ }^{1}$. A pesquisa foi motivada pela escassez de informações e estudos empíricos sobre a prática de professores de Psicologia no nível médio e pela necessidade de dados para subsidiar, articulando ensino e pesquisa, a formação de professores no curso de Licenciatura em Psicologia do Instituto de Psicologia da Universidade de São Paulo.

\footnotetext{
1 Parte dos resultados da pesquisa, obtidos por meio de entrevistas semiestruturadas, foi publicada no artigo Narrativas de professoras de Psicologia do Ensino Médio: entre memórias e reflexões (KOHATSU, 2015), que privilegiou a apresentação e a discussão das narrativas de 11 professoras sobre suas trajetórias formativas, suas concepções e suas práticas.
} 
Os dados foram coletados nos anos de 2011 e 2012 por meio de um questionário auto-aplicável enviado a 20 professores efetivos e concursados de Psicologia, lotados em diferentes Diretorias de Ensino da Capital, região metropolitana de São Paulo e interior.

\section{Breve histórico sobre o ensino de Psicologia e a situação atual}

Embora a disciplina de Psicologia não esteja mais presente no currículo do ensino médio da rede estadual paulista desde 2008, é importante recordar que desde o século XIX a Psicologia esteve presente nos currículos do ensino secundário e superior das instituições escolares brasileiras (cf. MASSIMI, 1993; PFROMM NETTO, 2001; ANTUNES, 2004), sendo as Escolas Normais, destinadas à formação de professores, o principal campo de ensino da disciplina. Deve-se destacar também que nas primeiras décadas do século XX, as concepções escolanovistas estreitaram as relações entre a educação e a Psicologia. (NAGLE, 1974). De acordo com Valetim, Pereira e Leite (2016), é neste período que a Psicologia assume o status de ciência aplicada que forneceria as bases científicas para a Pedagogia.

Na década de 1970, sob a Lei de Diretrizes e Bases da Educação Nacional LDB no 5.692/71, sancionada durante o período da ditadura civil-militar, que tornou compulsória a educação profissional no nível médio, as disciplinas de Psicologia, Filosofia e Sociologia foram retiradas do currículo do ensino secundário (LEITE, 2007; SOUZA, 2010) e introduzida a disciplina de Organização Social e Política do Brasil (OSPB) (SOLIGO; AZZI, 2009), parte do núcleo comum obrigatório de Estudos Sociais, juntamente com Geografia e História, conforme estabelecido pelo Artigo 1으 da referida Lei (BRASIL, 1971).

É interessante notar que a disciplina de Psicologia foi retirada do currículo do ensino secundário (correspondente ao ensino médio atual), mas foi mantida, em nível de 2ํ Grau, para o Magistério (VASCONCELOS, 1972, p. 135).

No início da década de 1980, a Lei Federal no 7.044/1982 revoga a profissionalização compulsória estabelecida pela LDB no 5692/71 e retoma a proposta de formação integral do aluno, possibilitando a presença de uma parte diversificada no currículo (MRECH, 2001, p. 149). Segundo Souza (2010, p.19) e Leite (1986, 2007), é nesse período que a Secretaria do Estado da Educação de São Paulo reintroduz a disciplina de Psicologia e, posteriormente, são constituídos grupos de trabalho coordenados pela Coordenadoria de Estudos e Normas Pedagógicas - CENP, Conselho Regional de Psicologia - CRP-SP e Sindicato de Psicólogos - SP com o intuito de promover a formação de professores de Psicologia, que resultou na publicação o livro Psicologia no ensino de 2o Grau: uma proposta emancipadora (CRP-SP, SINDICATO DE PSICÓLOGOS, 1987). 
Na década de 1990, é promulgada a Lei de Diretrizes e Bases da Educação Nacional no 9.394/1996, que inicialmente estabelecia no artigo 36 o domínio dos conhecimentos de Filosofia e a Sociologia pelo aluno do ensino médio, mas foi posteriormente revogada pela Lei no 11.864 , de 2008, que as tornou disciplinas obrigatórias nesse nível de ensino. A Psicologia, no entanto, não é mencionada na LDB 9.394/96 e só é referida como conteúdo transversal nos Parâmetros Curriculares Nacionais do Ensino Médio (1999), conforme observa Soligo (2010, p. 9).

Mesmo com a omissão na LDB 9.394/96, a disciplina de Psicologia continuou sendo ministrada na rede pública de São Paulo até o fim do ano de 2007, ocasião em que foram realizadas mudanças no currículo (Resolução SE no 92/2007), culminando na retirada definitiva da disciplina. Assim, no ano de 2008, a disciplina deixou de ser oferecida aos alunos do ensino médio e, desde então, os professores de Psicologia ${ }^{2}$ deixaram as salas de aula, tornando-se adidos e exercendo outras funções, tal como relatado em estudos anteriores (KOHATSU, 2013, 2015).

Segundo Magano (2010, p.15), enquanto não houver alterações nos artigos da LDB 9.394/96, referentes ao ensino médio, a reinserção da disciplina no currículo será dificultada, mas recorda o Projeto de Lei 105/2007, de autoria da deputada Luiza Erundina, que propõe uma emenda para inclusão da Psicologia. No entanto, tal como se tem observado, a tramitação do PL tem sido lenta por haver pouca mobilização da própria categoria, a despeito de eventuais ações das entidades representativas.

No âmbito da formação docente, é relevante ressaltar também que as Diretrizes Curriculares Nacionais para os cursos de graduação em Psicologia, Resolução CNE/CES 5/2011, estabelecem normas para a elaboração de projeto pedagógico complementar para a formação de professores. Embora a Resolução CNE/CES 5/2011 torne obrigatório o oferecimento da licenciatura pelas Instituições de Ensino Superior e facultativa ao aluno, não se pode desconsiderar que a profissão docente vem sofrendo crescente desvalorização (ALMEIDA; TARTUCE; NUNES, 2014) em função das precárias condições de trabalho, sobretudo nos sistemas públicos de educação (GATTI, 2010; LAPO; BUENO, 2003). Consequentemente, a procura pelos cursos de licenciatura torna-se pouco interessante. No caso da Psicologia, conforme Mrech (2001), a docência na educação básica tem sido historicamente pouco prestigiada pelos profissionais da área. Isso se reflete no pouco interesse de pesquisadores pelo tema, tal como apontado em revisão da literatura em estudos anteriores (KOHATSU, 2010). Há, inclusive, poucos estudos empíricos sobre o ensino de Psicologia no nível médio (DADICO, 2009; KOHATSU, 2013, 2015; SILVA, 2010) ou sobre a atuação do professor de Psicologia na Educação Básica (MACHADO; TIMM; STOBÄUS 2016).

\footnotetext{
2 Segundo dados obtidos junto ao Departamento de Recursos Humanos da Secretaria da Educação do Estado de São Paulo, no ano de 2008 havia 125 professores de Psicologia efetivos e concursados. No entanto, considerando os professores com outros contratos, o número estimado é muito maior. Pelo fato de muitos serem temporários, torna-se difícil obter uma estimativa que seja confiável.
} 
Embora a disciplina de Psicologia não figure mais no currículo do ensino médio da rede pública do Estado de São Paulo, é relevante apontar que os licenciados em Psicologia seguem lecionando nos cursos técnicos profissionalizantes em componentes curriculares fundamentados nos conhecimentos da área (PANDITA-PEREIRA, 2011, 2016; KOHATSU et al., 2016).

\section{Método}

Participaram da pesquisa 20 professora(e)s de Psicologia concursada(o)s e efetiva(o)s, sendo 19 do sexo feminino e um do sexo masculino, lotada(o)s em escolas de nove Diretorias de Ensino (Capital, região metropolitana e interior) da rede pública do Estado de São Paulo.

Como instrumento foi utilizado um questionário auto-aplicável, composto por questões objetivas.

Os dados obtidos foram sistematizados a partir dos itens do questionário, tal como poderá ser visto na parte dos resultados.

Após contato prévio com a(o)s professora(e)s com o intuito de esclarecer sobre a pesquisa e as condições de participação, foram enviados por correio eletrônico ou convencional o questionário e o Termo de Consentimento Livre e Esclarecido (TCLE). Após preenchimento, ambos foram devolvidos ao pesquisador.

\section{Resultados e discussão}

\section{a) Caracterização da(o)s participantes}

Na ocasião da coleta de dados, a(o)s participantes apresentavam idade entre 47 e 60 anos, apenas um professor (P8) do sexo masculino, sendo que quatro professoras já estavam aposentadas ( $\mathrm{P} 4,11,14,18)$.

Quanto à região de atuação, quatro estavam lotada(o)s em escolas da capital $(\mathrm{P} 3,5,8,18)$, duas em escolas da região metropolitana (P14 e 15) e as demais nas escolas do interior do estado ( $\mathrm{P} 1,2,4,6,7,9,10,11,12,13,16$, $17,19,20)$.

A(o)s professora(e)s ingressaram na rede estadual por meio de concursos públicos realizados no início da década de 1990, alguns assumindo o cargo logo após a aprovação enquanto outros tiveram de esperar em função da classificação. No entanto, a maioria relatou que já exercia a docência na rede estadual como professora(e)s temporária(o)s.

Em relação à formação acadêmica, duas participantes (P9 e 20) obtiveram graduação em Psicologia em universidades públicas, sendo que a(o)s demais foram graduada(o)s em instituições particulares ou confessionais. 
$\mathrm{Da}(0)$ s 20 participantes, 12 declararam ter cursado pós-graduação, sendo uma em nível de mestrado (P11), outra em nível de doutorado (P13) e a(o)s demais em cursos de especialização/lato sensu.

Após a retirada da disciplina de Psicologia do currículo do ensino médio, a(os) entrevistada(o)s informaram que passaram a exercer diversas funções pedagógicas e administrativas nas escolas e Diretorias de Ensino. Destacase que três professoras $(\mathrm{P} 1,12,20)$ já estavam atuando como coordenadoras pedagógicas e duas participantes estavam readaptadas de função $(\mathrm{P} 4,13)$ quando a disciplina foi retirada do currículo. No tocante às funções exercidas pela(o)s professora(e)s, foram citadas as mais diversas: coordenadoria pedagógica, biblioteca, auxiliar de secretaria, desenvolvimento de projetos, professor de biologia, professor de sociologia, professor mediador, dentre outros.

Foi solicitado aos participantes que informassem também as outras atividades profissionais que exerciam além da docência. Constatou-se que mais da metade da(o)s participantes, exerce ou já exerceu atividades de psicólogo concomitantemente ao exercício de docência. A Psicologia Clínica foi a mais reportada entre a(o)s participantes.

\section{b) Sobre a prática docente na disciplina de Psicologia}

Neste item são apresentados elementos relacionados ao ensino de psicologia: objetivos da disciplina, conteúdo programático, metodologia de ensino, avaliação, referências bibliográficas, participação dos alunos e posição sobre o retorno da disciplina ao currículo do ensino médio.

\section{- Objetivos da disciplina}

Em relação aos objetivos da disciplina, sete professoras (P1, 2, 6, 9, 14, 17, 18), declararam ter por objetivo "despertar", "introduzir", "proporcionar", "promover"o conhecimento da Psicologia como ciência; uma professora (P6) ainda detalhou "conhecer a área da Psicologia (objeto de estudo, métodos e áreas de atuação profissional)"; uma professora (P5) também fez referência ao conhecimento do campo de atuação do psicólogo, mas sem mencionar o termo ciência. Para algumas professoras o acesso ao conhecimento científico da Psicologia visava contribuir para a "formação geral do aluno" (P6); "promover uma visão mais crítica do mundo" (P1, 6, 14); "proporcionar ao aluno maiores esclarecimentos sobre a fase da vida pela qual estão passando e auxiliá-los em suas escolhas" (P9); "facilitadora do exercício da cidadania consciente e participativa" (P14); "autorreflexão, empatia, respeito ao outro, ao ambiente e à sociedade em geral" (P18).

Merece ser destacado também a frequência de expressões como "visão mais crítica do mundo" (P1); "mundo mais justo e igualitário" (P5); "posicionamento crítico diante do mundo" (6); "inserir o aluno na sociedade como ser questionador, reflexivo (...), estimular a problematização e expressão do senso crítico" (P7), "desenvolvimento de uma consciência crítica, capaz de atuar de forma participativa e libertadora do processo de transformação da 
estrutura social" (P10); "proporcionar uma visão mais crítica dos fenômenos sociais" (P11); "formação do indivíduo crítico e participante na sociedade" e "compreender a realidade social" (14); "transformação na sua vida e no mundo" (P15); "formação de indivíduos conscientes, críticos e transformadores" (P19); "ação mais efetiva na sociedade" e "transformações na sociedade" (P20).

Algumas professoras manifestaram atenção aos aspectos relacionados à adolescência, juventude e temas relacionados como "identidade", "autoestima", "autoconhecimento", "afetividade", "sexualidade", "gravidez", "DSTAids", "drogas", "escolha profissional”, (P2, 3, 5, 6, 7, 9, 11, 12, 15, 16, 17, 18, 20) e nota-se que não prevalece a compreensão naturalizada e individualista dos processos psíquicos, mas abordagens que relacionam esses temas com a realidade social.

\section{- Conteúdo programático}

Os conteúdos declarados pelas professoras apontam coerência com os objetivos mencionados, tal como pode ser visto. Psicologia como ciência foi citada por várias professoras $(\mathrm{P} 1,2,3,6,7,10,11,14,15,18)$, no entanto, uma professora (P9) declarou ter como objetivo trabalhar a Psicologia como ciência, mas não fez referência a esse ponto em seu conteúdo programático, diferentemente das professoras $(\mathrm{P} 3,7,10,11)$ que não explicitaram o ponto nos objetivos, mas apresentaram na parte dos conteúdos.

Algumas professoras referiram-se às teorias, mas apenas duas professoras nomearam as abordagens teóricas, como Psicologia Comportamental, Psicanálise e Gestalt (P1 e 18) e duas citaram áreas da Psicologia como a Psicologia da Personalidade, Psicologia do Desenvolvimento, Psicologia Social (P1 e 16); algumas professoras citaram o conceito de inteligência $(\mathrm{P} 11,15,18$ e 20), inteligência emocional $(\mathrm{P} 11,13)$ e inteligências múltiplas (P14).

Um aspecto que merece ser destacado refere-se ao trabalho com temas, citado por quase todas entrevistadas, com exceção apenas daqueles que não declararam os conteúdos trabalhados nos questionários $(\mathrm{P} 4,8)$. O depoimento de uma professora (P3) é bem ilustrativo:

A disciplina de Psicologia sempre teve uma grande liberdade sobre os componentes curriculares, na realidade nunca houve oficialmente um currículo oficial como atualmente foi implantado no Estado de São Paulo. Portanto, todo início do ano letivo eu elencava alguns temas que considerava relevantes para a vida dos alunos e os apresentava, informando sobre o que discorriam e com quais objetivos seriam trabalhados e, juntos, decidíamos os conteúdos (temas) e a sequência em que seriam apresentados. Também oferecia a oportunidade para que sugerissem outros temas de interesse ou então deixávamos em aberto a possibilidade de ingresso sobre um novo tema, conforme a necessidade atual fosse despertando (P3). 
Os temas mais frequentes foram: "adolescência", mencionado por 10 professoras $(\mathrm{P} 1,2,5,6,9,10,14,15,19$, 20) e outros associados como "sexualidade e DST-AIDS" (P2, 6, 9, 10, 13, 14, 16, 19 e 20), "drogas" (2, 5, 6, 9, 10, 19 e 20), "autoestima/autoconhecimento/identidade" (P5, 7, 9, 14 e 20) e "violência" (P6, 10, 14, 15). "Saúde mental", "normalidade-anormalidade", "transtornos psíquicos" também foram citados como conteúdos trabalhados por nove professoras (P1, 2, 5, 6, 7, 11, 14, 18 e 20). Alguns temas da Psicologia Social também foram mencionados como "preconceito" ( $7,14,16,19)$ e "meios de comunicação de massa"(P6, 11 e 14). Por fim, um dos temas mais citados foi relacionado à "escolha profissional" e "trabalho" (P1, 2, 5, 6, 7, 9, 10,11, 13, 15, 16, 19 e 20), sendo que duas professoras referiram-se explicitamente à "orientação profissional” (P15 e 16). Os temas citados pelas entrevistadas nesta pesquisa corroboram com os resultados obtidos em outros estudos (KOHATSU, 2013; SILVA, 2011), no qual os participantes referiram-se aos mesmos temas, com destaque para o trabalho com a escolha profissional e trabalho.

\section{- Metodologia de ensino}

$\mathrm{Da}(\mathrm{o}) \mathrm{s}$ vinte professora(e)s entrevistada(o)s, $12(\mathrm{P} 1,2,3,5,6,7,8,10,14,15,17,18)$ declararam recorrer às aulas expositivas, sendo que cinco $(\mathrm{P} 1,6,14,17,18)$ destacaram a aula expositiva dialogada, ou seja, exposição com interação e participação dos alunos.

A leitura, análise e interpretação de textos, de natureza teórica e/ou jornais e revistas, foram mencionadas por 15 professoras $(\mathrm{P} 2,3,4,6,7,9,10,11,12,14,16,17,18,19$ e 20); uma professora (P12) informou que a leitura era permanente. Importante destacar que cinco professoras referiram-se explicitamente a conteúdos teóricos (P4, 9, 12, 18 e 19) presente no material da leitura.

A(o)s professora(e)s informaram também o uso de estratégias diversificadas como seminários, debates, dinâmicas de grupo, rodas de conversa, jogos e brincadeiras, teatro (P1, 2, 3, 4, 5, 6, 7, 8, 9, 10,11, 12, 14, 15, 16, 18, 19 e 20) e uso de diversos recursos e materiais como poemas, crônicas, histórias em quadrinhos, filmes e músicas (P1, 2, 3, 6, $7,9,10,11,12,14,15,17,18$ e 19). Duas professoras informaram que faziam atividades extra-classe, como visitas a instituições como APAE, AACD, GRAAC, AA (3) e visitas a universidades (7).

Algumas professoras justificaram o uso dessas metodologias, estratégias e recursos: "Os alunos eram incentivados a expressarem as suas vivências" (P5); "levantamento de conhecimentos prévios dos alunos sobre o tema" (P12); "A cada novo assunto utilizava uma estratégia diferente objetivando aproximar os conhecimentos da Psicologia ao cotidiano, estimulando a participação dos alunos para o entendimento de conceitos que, na maioria das vezes, não fazia parte do dia-a-dia." (P18); "O objetivo era sempre fazer o aluno participar, expor suas idéias, respeitar pontos de vista diferentes, despertando seu senso crítico (...)” (P20). 
Pelas informações coletadas, nota-se que a(o)s professora(o)s tinham a preocupação em trabalhar os aspectos teóricos da Psicologia, mas de modo significativo aos alunos, buscando metodologias, estratégias, materiais e recursos para que os alunos pudessem expressar os conhecimentos prévios relacionados aos assuntos/temas tratados e que estabelecessem relações com o cotidiano vivido. As formas de trabalho e as justificativas relatadas vão ao encontro dos dados coletados e discutidos em outro estudo realizado também com professores de Psicologia do ensino médio (KOHATSU, 2013).

\section{- Avaliação}

Pela análise das respostas dadas, nota-se que toda(o)s a(o)s professora(o)s que responderam à questão da avaliação realizavam diversos procedimentos. A realização de prova foi mencionada por $17(\mathrm{P} 1,2,3,4,6,8,9,10$, $11,12,14,15,16,17,18,19$ e 20), mas também aplicadas de diferentes modos: quatro se referiram à prova individual (P3, 8, 15 e 18), sendo que uma delas (P3) especificou "individual sem consulta"; prova escrita em dupla e com consulta (P16); prova em grupo (P3, 8 e 18); com questões abertas ou dissertativas (P1, 4, 18 e 19); com questões objetivas ou múltipla escolha (P17 e 19); sobre conteúdo teórico (9). Embora todos os entrevistados tenham declarado a realização de prova como procedimento de avaliação, nota-se realizavam conjuntamente formas alternativas como trabalhos individuais ou em grupo (P1, 7, 8, 10, 11, 14, 15 e 20); seminários (P6, 8, 16, 19 e 20); participação em aula (P1, 2, 3, 4, 5, 6, 9, 11, 14, 15, 16, 17 e 20); auto-avaliação (P1 e 2). Algumas professoras referiram-se também à avaliação diária ou contínua $(\mathrm{P} 4,5,7,11,12,14$ e19).

Nota-se que era comum à mesma professora combinar diversos procedimentos de avaliação, mas chama atenção que a prova escrita, citada por 17 professora(o)s, e a participação em aula, referida por 13, foram as mais utilizadas.

Sobre o rendimento dos alunos, o depoimento de uma professora (P19) é ilustrativo: "De forma geral, o interesse dos alunos era bom, pois havia envolvimento nas atividades apresentadas, as notas obtidas eram satisfatórias e através de comentários dos próprios alunos à direção da escola de que gostavam da disciplina."

\section{- Referências bibliográficas utilizadas pelos professores}

Tal como apontado em estudo anterior (KOHATSU, 2013), o livro mais citado pelas professoras (P1, 2, 5, 6, 7, 10, 13, 14, 15, 16, 17 e 19) foi Psicologias: Uma introdução aos estudos da Psicologia, de autoria de Ana Mercês Bock, Odair Furtado e Maria de Lourdes T. Teixeira $\left(1997^{3}\right)$. Outros autores foram citados em menor freqüência, como

3 Uma professora citou a edição de 1994 e outra citou a edição de 1995. 
Içami Tiba (P3, 10), para tratar do tema das drogas; Rosely Sayão (P9), como referência para o tema da sexualidade; Antônio Ciampa (P19), para discutir identidade; Silva Lane e Wanderley Codo (19), como referência da Psicologia Social, e ainda Celso Antunes (P14). Uma professora citou livros sobre dinâmica de grupo. Duas professoras (P13 e 19) citaram a Proposta Curricular de Psicologia para o Ensino de 2o grau, edições de 1986 e 1992, respectivamente; uma professora (P14) citou os Parâmetros Curriculares Nacionais do Ensino Médio - PCNEM. Duas professoras mencionaram romances: Pequenas histórias, de autoria de José Saramago (P14) e O alienista, de Machado de Assis (P17).

Além das obras citadas, as professoras referiram-se também ao uso de revistas, jornais, materiais da Internet $(2,3,5,7,11,12,17$ e 20). Algumas entrevistadas explicaram que usavam materiais, como apostilas e coletâneas, preparados por elas mesmas $(1,4,6,7,11,12,18$ e 19) porque "não havia um material bibliográfico específico" (7), "não havia um livro de apoio ou apostila" (11) ou eram "construídos em sala com os alunos" (18); algumas professoras combinavam esses materiais feitos por elas com os livros de referência citados.

\section{- Participação dos alunos}

A(o)s professora(o)s foram unânimes sobre a boa participação dos alunos nas aulas de Psicologia. Algumas frases são bem ilustrativas: "As aulas despertavam bastante interesse e curiosidade nos alunos" (1); "Conquistava a grande maioria dos alunos" (3); "Os alunos demonstravam muito interesse e participavam bem" (7); "Eles adoravam as aulas e participavam bastante" (15); "Eram extremamente contagiantes, as discussões em sala de aula eram produtivas e instrutivas, os alunos participavam de forma efusiva (...)" (18).

Uma das professoras (5), no entanto, observa a diferença entre a participação dos alunos da manhã e do período noturno, como se pode ver:

"No período diurno a resposta, o interesse e a participação dos alunos eram mais satisfatórios do que no periodo noturno. Envolviam-se mais com os conteúdos e a maioria demonstrava grande interesse em construir com consciência um futuro profissional favorável. Tendiam inclusive a se mostrarem afetivos ao professor. (...). As turmas noturnas tendiam mais para a apatia, indisciplina e/ou rebeldia. Muitos alunos iam além da hostilidade e mostravam-se violentos, verdadeiros 'bomba relógios'.” (P5)

Outra professora (17), contudo, demonstrou uma percepção diferente em relação aos alunos do noturno: "Na época os alunos ouviam, gostavam. Principalmente os alunos do noturno." 
As entrevistadas explicam que o interesse era devido aos temas trabalhados em sala, relacionados às vivências e ao cotidiano dos alunos: eram "assuntos e temas vivenciadas por eles e ou que podiam relacionar com o cotidiano" (1); "os assuntos eram escolhidos de acordo com as necessidades dos adolescentes" (4); "abordava assuntos do dia a dia (...) orientações sobre perspectiva profissional e inserção no mundo do trabalho" (7); "eu procurava tratar de assuntos relativos ao seu cotidiano, além do que tinham a liberdade de propor temas, falar de suas dificuldades, seus sonhos, enfim era o espaço para buscarem a compreensão de si mesmos.” (20).

Como forma de ilustrar o interesse dos alunos, uma das professoras (14) comentou que foi convidada algumas vezes para ser homenageada ou para ser paraninfa; outra professora (11) escreveu que "alguns alunos gostaram tanto de Psicologia que depois resolveram cursar a faculdade e se tornavam meus alunos novamente". E outra professora (6) recordou que "quando a disciplina foi retirada do currículo do Ensino Médio (alunos) fizeram um abaixo assinado para não retirarem."

\section{- Sobre o retorno da disciplina ao currículo do ensino médio}

Somente um professor manifestou-se contrário ao retorno da disciplina de Psicologia ao currículo do ensino médio. É interessante observar que entre os entrevistados, esse professor havia informado que não ministrava a disciplina há muito tempo e por isso não respondeu alguns itens do questionário por não se recordar.

As demais professoras mostraram-se favoráveis ao retorno da disciplina, mas uma delas (2) ressaltou: "desde que fosse ministrada de forma adequada". As justificativas mais frequentes estavam relacionadas ao interesse dos alunos e pelo fato da disciplina de Psicologia tratar de assuntos do cotidiano dos jovens, tal como mostram alguns depoimentos: "Ficavam mais críticos" (1); "ajuda os alunos no autoconhecimento, ajuda a questionar a situações do cotidiano" (6); "Procurava-se levar o aluno a refletir sobre sua vida, aspectos do dia a dia" (7); "por ser um espaço de debate e esclarecimento de temas pertinentes a vida dos adolescentes" (9); "Era uma das poucas disciplinas que se preocupava com o desenvolvimento e conhecimento da formação do ser humano nos aspectos biopsicossocial, era um ensino contextualizado, uma aprendizagem significativa" (11); "ela (Psicologia) contribui intensamente para a construção do pensamento crítico e conscientização do aluno sobre sua atuação no mundo, fortalecendo uma postura responsável e coletiva tão necessárias numa sociedade democrática." (19).

Duas professoras escreveram que alguns ex-alunos recordam das aulas: "Até hoje, alguns alunos que encontro fazem referências positivas das aulas. Acho inclusive que contribuía para o autoconhecimento, numa fase tão difícil como a adolescência." (1); "meus alunos gostavam muito, aprendiam muito, achavam que era importante para a vida deles e até hoje quando os encontros comentam sobre as experiências agradáveis das aulas" (4). 


\section{Algumas considerações sobre a proposta de trabalho com temas: uma ligeira retomada histórica}

Os dados obtidos sobre a(o)s professora(e)s e suas práticas em sala de aula - objetivos, conteúdos, metodologia e referências bibliográficas referentes ao ensino de Psicologia - assemelham-se aos resultados encontrados em pesquisa realizada anteriormente (KOHATSU, 2013). Assim como no estudo anterior, nota-se que a(o)s professora(e)s visavam à formação crítica do jovem estudante do ensino médio. Esse dado vai ao encontro da proposta defendida pela Comissão de Ensino formada pelo CRP-SP, Sindicato de Psicólogos-SP e CENP, retomada em um artigo publicado por Leite (2007):

Como ponto de partida, assumimos que a Psicologia, enquanto área de produção de conhecimento científico e também como área de exercício profissional, tem uma contribuição fundamental para o desenvolvimento educacional dos jovens do ensino médio. Tal contribuição relaciona-se com o processo de constituição destes jovens como cidadãos críticos e participantes, auxiliando-os na superação do processo de alienação, muito presente em uma sociedade injusta como a nossa. (LEITE, 2007, p. 11).

De modo semelhante aos professores entrevistados na pesquisa anterior (KOHATSU, 2013), a(o)s professora(e)s participantes desta pesquisa declararam também terem trabalhado com temas próximos da vivência dos alunos, nesse aspecto também se aproximando da proposta curricular apresentada pela Comissão:

Ao optar por uma organização por temas, a comissão acreditava na possibilidade de abordar assuntos que, de um lado, possibilitassem uma relação com as condições de vida dos jovens e, por outro, permitissem uma análise teórica, a partir das contribuições das várias correntes psicológicas existentes (LEITE, 2007, p. 14).

A proposta do trabalho com temas foi baseada na avaliação feita pela Comissão de Ensino junto aos professores de Psicologia da rede, que apontava que os cursos baseados nas teorias psicológicas mostravam-se burocratizados e apenas reproduziam as aulas ministradas na graduação, contribuindo pouco para a formação crítica dos jovens. Nesse aspecto, é importante recordar que a(o)s entrevistada(o)s, a despeito de trabalharem com temas, não deixaram de ministrar as teorias clássicas como a Psicologia Comportamental, a Psicanálise e a Gestalt, como apontado anteriormente. 
Soligo e Azzi (2008) também problematizam o dualismo teorias-temas frequentemente presente na discussão dos conteúdos a serem ministrados no ensino de Psicologia no nível médio. As autoras criticam a oposição teoria-temas, mostrando que as teorias psicológicas e os conceitos propiciam a base para a compreensão dos problemas da contemporaneidade, representados pelos temas. Assim, não se trata de oposição ou dualismo, mas de complementaridade. Nessa perspectiva, as autoras mostram como algumas teorias psicológicas clássicas contribuíram para a compreensão das questões contemporâneas, como a psicanálise de Freud sobre o inconsciente e a sexualidade humana; a abordagem de Skinner sobre o comportamento; a psicologia sócio-cognitiva sobre a aprendizagem; a teoria de Piaget sobre a inteligência e as contribuições da perspectiva histórico-cultural de Vigotski para a compreensão das relações entre a cultura e o psiquismo. O modo como as autoras entendem a relação de complementaridade entre teorias e temas vai ao encontro da proposta defendida pela Comissão de Ensino (CRP-SP, Sindicato de Psicólogos-SP e CENP), citada anteriormente, e da organização do livro Psicologias (BOCK; FURTADO; TEIXEIRA, 1999), o livro de referência mais citado pelas entrevistadas, que também se organiza em temas em uma de suas partes.

A proposição do trabalho com temas, fundamentado em teorias, pode ser uma alternativa interessante na medida em que articula os conteúdos a serem trabalhados com uma abordagem metodológica que aproxima o conhecimento escolar da vivência dos alunos. Entretanto, ainda que temas e teorias estejam articulados, o campo teórico da Psicologia pode ser visto de modo fragmentado pelo aluno se a relação entre as teorias e seus fundamentos epistemológicos não forem discutidos. Nessa proposta, a ênfase é dada à discussão dos temas e a discussão teórica se subordina a estes, não sendo aprofundada a questão da produção do conhecimento científico na Psicologia. Pode-se questionar se esta seria uma tarefa a ser realizada no ensino médio e se os alunos teriam requisitos para realizá-la. Se houver o entendimento de que não, fica em aberto a questão da fragmentação do campo teórico da Psicologia e como isso seria abordado junto aos alunos.

A proposta de trabalho pedagógico orientado por temas aproxima-se também do princípio da contextualização, tal como estabelecido na Resolução CNE/CEB no 02/2012, que define as Diretrizes Curriculares Nacionais para o Ensino Médio - DCNEM, no artigo 5ํㅜ, item VI. É interessante notar que o princípio da contextualização, assim como o da interdisciplinaridade, já estava citado na Resolução CNE/CEB no 3/1998, orientada pela pedagogia das competências, revogada pela Resolução CNE/CEB no 02/2012, fundamentada em outras bases teóricas e políticas, críticas à concepção anterior.

Lopes (2002) realiza uma análise crítica do modo como o conceito contextualização foi apropriado nos Parâmetros Curriculares Nacionais para o Ensino Médio (BRASIL, 1999), citando algumas de suas referências 
O documento oficial afirma explicitamente que esse conceito se fundamenta em David Stein e sua idéia de uma aprendizagem situada (BRASIL, 1999, v. 1, p.141-142), com base na vivência de situações do dia-a-dia, segundo os interesses dos alunos, e no desenvolvimento de atividades desvinculadas da pura transmissão de conceitos. Para Stein (1998), situar uma aprendizagem significa colocar o pensamento e a ação em um lugar específico de significado, envolver os aprendizes, o ambiente e as atividades para produzir significado. Todo conhecimento é construído de forma situada, em determinado contexto, de maneira a ser transferido para situações similares (LOPES, 2002, p. 391).

Segundo a autora, o documento recupera ainda ideias de Dewey, Bruner, Piaget e Vigotski, apropriando-se delas para justificar o ajustamento às demandas da nova economia, entenda-se neoliberal, que orientaram as reformas do Estado e da educação na década de 1990, conforme já mostraram autores como Frigotto e Ciavatta (2003).

A aprendizagem situada ou contextualizada, defendida nos PCNEM (BRASIL, 1999), visa "retirar o aluno da condição de espectador passivo, em produzir uma aprendizagem significativa..." (LOPES, 2002, p. 391-392) e valorizar o conhecimento prévio dos alunos e das vivências do cotidiano, com os quais os saberes escolares devem manter uma relação intrínseca. Nos PCNEM, esses saberes prévios e as vivências do cotidiano são incluídos em uma noção de contexto restrita, com vistas à resolução de problemas e desenvolvimento de competências.

Para Lopes (2002), há um caráter híbrido presente nos PCNEM, que mescla concepções distintas com o eficientismo social visando uma associação estreita entre educação e o mundo produtivo. Importante também destacar, tal como fez Lopes (2002), que se substitui o conceito de cotidiano e de valorização dos saberes populares pelo conceito de contextualização, sugerindo que se tratam do mesmo enfoque educacional.

Desse modo, ocultam-se os pressupostos que distinguem concepções de educação que são contraditórias, como a educação libertadora de Paulo Freire ${ }^{4}$, que defende a educação como ato político visando à emancipação dos educandos, por um lado e, por outro, a pedagogia das competências, que visa o ajustamento às demandas do mercado de trabalho.

Em outro trabalho, Lopes e Macedo (2011) mostram a reedição da racionalidade técnica tyleriana ${ }^{5}$, de matriz comportamental, nas reformas curriculares dos anos 1990, ocasião em que se propõe a pedagogia das

${ }_{4}^{4}$ Como outro exemplo histórico de apropriação das ideias progressistas podemos recordar Freitag, citada por Patto (1984, p.66), que adverte o modo como o MOBRAL, a despeito de basear-se em outra concepção, apropria-se das técnicas de alfabetização de Paulo Freire, 'extraindoas de seu contexto filosófico e político...'.

5 Citando Ralph Tyler, uma das principais referências das propostas curriculares no Brasil, até meados dos anos de 1980, conforme Lopes e Macedo (2011, p. 43). 
competências. No entanto, as autoras esclarecem que não se trata de recuperação desse modelo, mas de uma hibridização dos sentidos construídos pela proposta tyleriana com outras referências, como a matriz estruturalista desenvolvida na França, na década de 1970, baseada na concepção de esquema de Piaget.

Ramos (2003), autora de inúmeros trabalhos voltados à crítica da pedagogia das competências, também mostra que o construtivismo piagetiano, especialmente o conceito de equilibração, constituiu-se no aporte psicológico da pedagogia das competências:

As competências seriam as estruturas ou os esquemas mentais responsáveis pela interação dinâmica entre os saberes prévios do indivíduo - construídos mediante as experiências - e os saberes formalizados (RAMOS, 2003, p. 98 - grifos nossos).

Lopes e Macedo (2011) apontam também a aproximação entre a racionalidade tyleriana e o modelo de elaboração curricular proposto por César $\mathrm{Coll}^{6}$, que dá especial atenção à dimensão psicológica no currículo, baseado em autores como Piaget e Vigotski.

A partir de outra perspectiva teórica, Duarte (2004) critica o ecletismo e a justaposição de teorias distintas na educação, tal como ocorre na pedagogia do "aprender a aprender", um dos pilares defendidos nos PCNs ${ }^{7}$. Aliás, Duarte faz questão de explicitar sua posição categoricamente negativa em relação a alguns autores como Coll, Palácios e Marchesi, que propõem a aproximação da psicologia de Vigotski ao movimento construtivista de Piaget (DUARTE, 2004, p. 19). Especialmente em relação à proposta de Coll, Duarte escreve:

Aliás, não concordamos com César Coll (1994, p.116-134) quando este define, como "marco psicológico para o currículo escolar", um conjunto eclético (apesar do autor dizer que pretende evitar o ecletismo) e pragmático de princípios psicopedagógicos, mesclando conceitos de Piaget, Vigostki e Ausubel, entre outros. Como um desses princípios, César Coll define o "aprender a aprender como o objetivo mais ambicioso, mas irrenunciável, da educação escolar" (DUARTE, 2004, p. 20).

6 César Coll (1997) foi uma referência importância na reforma curricular na Espanha, na década de 1980 e atuou como assessor na reforma curricular no Brasil, na década de 1990.

7 Ver Relatório Para UNESCO da Comissão Internacional sobre Educação para o século XXI, conhecido como Relatório Jacques Delors (1998), citado nos PCN (Brasil, 1999). 
Em seu livro, Duarte (2004) dedica-se à crítica da apropriação neoliberal e pós-moderna da teoria vigostkiana presente no "aprender a aprender", historicamente presente no pensamento educacional brasileiro ${ }^{8}$, desde os primórdios do movimento escolanovista. Para o autor, o revigoramento do "aprender a aprender" ocorre a partir da década de 1980, com a difusão do movimento construtivista, que tem a epistemologia genética de Piaget como a principal referência. Aliás, para Duarte, o construtivismo pode ser entendido como uma espécie de atualização da Escola Nova, cujos pressupostos já mostravam afinidade com a teoria piagetiana, tal como entendido pelo próprio Piaget (1970). Conforme Coll, citado por Duarte (2004, p.62), o princípio unificador de distintas correntes da psicologia educacional seria a defesa do papel construtivo ou ativo do aluno.

É interessante observar que as críticas ao suposto "intelectualismo teórico" da escola tradicional e seu método de ensino "conteudista", em diferentes momentos históricos, tornaram-se bandeira comum do movimento escolanovista, do construtivismo e da pedagogia das competências que, baseados nos conhecimentos da Psicologia, propuseram e defenderam a ênfase na atividade do aluno, do "saber-fazer" e da dimensão mais instrumental da educação escolar em detrimento do conhecimento teórico e do trabalho intelectual. Deve-se destacar também que as críticas à ineficiência da escola tradicional surgiram em momentos em que se tornou necessário justificar as reformas educacionais com vistas ao ajustamento às demandas sociais e econômicas.

\section{Considerações finais}

Considerando o predomínio da razão instrumental em todas as esferas da vida, sobretudo na educação escolar, tornam-se mais claros os motivos que levaram a retirada da disciplina de Psicologia do currículo do ensino médio, cada vez mais estandardizado para atender as demandas do setor produtivo globalizado e tendo reduzido seu caráter de formação geral e de crítica social.

No entanto, contraditoriamente, ainda que ausente como disciplina curricular em alguns momentos, a Psicologia manteve-se presente como importante referência do pensamento educacional brasileiro, sendo apropriada para dar fundamento teórico e metodológico à modernização da educação revelando, desse modo, sua função ideológica para justificar o ajustamento da educação ao mundo produtivo. Por ironia do destino, ao contribuir para a construção de uma concepção mais pragmática de educação, acabou sendo excluída do currículo.

\footnotetext{
8 A perseverança do ideário liberal no pensamento educacional brasileiro, a despeito das críticas que foram feitas a ele, é observada também por Patto (2015), ao analisar as publicações da Revista Brasileira de Estudos Pedagógicos.
} 
$\mathrm{Na}$ medida em que as bases epistemológicas e políticas da Psicologia são ignoradas ou ocultadas, os conhecimentos desse campo científico se mostram fragmentados e desconexos, permitindo justaposições teóricas ecléticas e amalgamadas para atender a necessidade de justificar a ordem social vigente ${ }^{9}$ e anulando o potencial de crítica à ideologia.

Apontar a importância do trabalho intelectual, da valorização da dimensão teórica no ensino da Psicologia, não significa fazer a defesa nostálgica do retorno à educação tradicional, até porque as condições históricas e sociais para o desenvolvimento do trabalho intelectual na escola foram reduzidas pelo clima cultural do entretenimento e do ativismo irrefletido. Contudo, para se evitar a atitude de resignação e conformismo às tendências hegemônicas ${ }^{10}$ na educação e na sociedade, deve-se recordar que a educação ainda é um importante campo de disputa das idéias e, por esse motivo, a crítica não deve ser abandonada.

Para finalizar, seria importante apontar que as discussões sobre o ensino de Psicologia no nível médio remetem a reflexões mais gerais sobre o currículo e a formação dos jovens das escolas públicas, revelando as contradições e as disputas que são travadas historicamente na educação e na sociedade.

\section{Referências}

ANTUNES, Mitsuko Aparecida Makino. A psicologia no Brasil no século XX: desenvolvimento científico e profissional. In: MASSIMI, Marina; GUEDES, Maria Carmo do. História da Psicologia no Brasil: novos estudos. São Paulo: EDUC: Cortez, 2004. p. 3-4.

BRASIL. Lei no 5.692, de 11 de agosto de 1971. Fixa Diretrizes e Bases para o ensino de 1ํ e 2o graus, e dá outras providências. Diário Oficial da União, Brasília, DF, 12 ago. 1971. Seção I. Disponível em: <http://www2.camara.leg.br/legin/fed/lei/1970-1979/lei-569211-agosto-1971-357752-publicacaooriginal-1-pl.html>. Acesso em 12 jun. 2017.

BRASIL. Lei no 9.394, de 20 de dezembro de 1996. Estabelece as Diretrizes e Bases da Educação Nacional. Diário Oficial da União, Brasília, DF, 20 dez. 1996. Seção I. Disponível em: <http://www.planalto.gov.br/ccivil_03/leis/L9394.htm> Acesso em: 02 out. 2016.

BRASIL. Parâmetros Curriculares Nacionais para o Ensino Médio: Ciências Humanas e suas Tecnologias. Parte IV, 1999. Disponível em: <http://portal.mec.gov.br/seb/arquivos/pdf/cienciah.pdf>. Acesso em: 05 out. 2016.

BRASIL. Resolução no 8, de 7 de maio de 2004. Institui Diretrizes Curriculares Nacionais do curso de graduação em Psicologia. Diário Oficial da União, Brasília, DF, 18 maio. 2004. Seção I. Disponível em: <http://portal.mec.gov.br/cne/arquivos/pdf/rces08_04.pdf>. Acesso em: 02 out. 2016.

9 Inúmeros exemplos podem ser dados, mas apenas a título de ilustração pode ser recordado o período em que predominaram as teses eugenistas e higienistas, tal como discutido por Patto (2015).

${ }^{10}$ Hegemonia segundo Gramsci, citado por Williams (2011). 
BRASIL. Projeto de Lei n. 105, de 12 de fevereiro de 2007. Altera dispositivos do art. 36 da Lei no 9.394, de 20 de dezembro de 1996 , que estabelece as Diretrizes e Bases da Educação Nacional. Câmara dos deputados, Brasília, DF, 12 fev. 2007. Disponível em: <http:// www.camara.gov.br/proposicoesWeb/fichadetramitacao?idProposicao=340480 > . Acesso em: 12 jun. 2017.

BOCK, Ana Mercês Bahia; FURTADO, Odair; TEIXEIRA, Maria de Lourdes Trassi. Psicologias: uma introdução ao estudo de Psicologia. 13. ed. São Paulo: Saraiva, 1999.

COLL, César. Psicologia e currículo. São Paulo: Ática, 1997.

CONSELHO REGIONAL DE PSICOLOGIA DE SÃO PAULO E SINDICATO DE PSICÓLOGOS NO ESTADO DE SÃO PAULO. Psicologia no ensino de $2^{\circ}$ Grau: uma proposta emancipadora. São Paulo: Edicon, 1987.

DADICO, Luciana. Práticas educacionais distintas: a psicologia no ensino médio paulista. Cadernos de Pesquisa. v. 39, n. 137, p. 420-440, 2009. Disponível em: <http://www.scielo.br/pdf/cp/v39n137/v39n137a06.pdf>. Acesso em: 12 jun. 2017.

DUARTE, Newton. Vigotski e o "aprender a aprender": crítica às apropriações neoliberais e pós-modernas da teoria vigotskiana. Campinas: Autores Associados, 2004.

FRIGOTTO, Gaudêncio; CIAVATTA, Maria. Educação básica no Brasil na década 1990: subordinação ativa e consentida à lógica do mercado. Educ. Soc., Campinas, v. 24, n. 82, p. 93-130, 2003. Disponível em: <http://www.scielo.br/pdf/es/v24n82/a05v24n82.pdf>. Acesso em: 12 jun. 2017.

GATTI, Bernadete. Formação de professores no Brasil: características e problemas. Educação \& Sociedade, v. 31, n. 113, p. 1355-1379, 2010. Disponível em: <http://www.scielo.br/pdf/es/v31n113/16.pdf>. Acesso em: 12 jun. 2017.

KOHATSU, Lineu Norio. A reinserção da disciplina de Psicologia no ensino médio: as especificidades da Psicologia e os desafios do atual contexto educacional. Psicologia Ensino \& Formação, v. 1, n. 1, p. 53-66, 2010. Disponível em: <http://pepsic.bvsalud.org/pdf/ pef/v1n1/06.pdf>. Acesso em: 12 jun. 2017.

KOHATSU, Lineu Norio. O ensino de Psicologia no ensino médio: relatos de professores da rede pública do Estado de São Paulo. Psicologia: Ensino \& Formação, 4, n. 2, p. 34-64, 2013. Disponível em: <http://pepsic.bvsalud.org/pdf/pef/v4n2/v4n2a04.pdf>. Acesso em: 12 jun. 2017.

KOHATSU, Lineu Norio. Narrativas de professoras de Psicologia do ensino médio: entre memórias e reflexões. Psicologia da Educação, v. 41, p. 65-81, 2015. Disponível em: <file:///C:/Users/lucas/Downloads/27843-73393-1-SM.pdf>. Acesso em: 12 jun. 2017.

KOHATSU, Lineu Norio et. al. A formação de professores de Psicologia e a docência nos cursos técnicos profissionalizantes. In: MASSABNI, V. M.; PIPITONE, M. A. P. Formação de professores para a educação profissional. Curitiba: CRV, 2016.

LAPO, Flavinês Rebolo; BUENO, Belmira Oliveira. Professores, desencanto com a profissão e abandono do magistério. Cadernos de Pesquisa, v. 118, p. 65-88, 2003. Disponível em: <http://www.scielo.br/pdf/cp/n118/16830.pdf>. Acesso em: 12 jun. 2017.

LEITE, Sérgio Antônio da Silva. O Ensino de Psicologia no Segundo Grau. Psicologia: Ciência e Profissão, v. 6, n. 1, p. 9-12, 1986. Disponível em: <http:/www.scielo.br/pdf/pcp/v6n1/03.pdf>. Acesso em: 12 jun. 2017.

LEITE, Sérgio Antônio da Silva. Psicologia no Ensino Médio: desafios e perspectivas. Temas em Psicologia, v. 15, n. 1, p. 11-21, 2007. Disponível em: <http://pepsic.bvsalud.org/pdf/tp/v15n1/03.pdf>. Acesso em: 12 jun. 2017. 
LOPES, Alice Casimiro. Os Parâmetros Curriculares Nacionais para o Ensino Médio e a submissão ao mundo produtivo: o caso do conceito de contextualização. Educ. Soc., Campinas, v. 23, n. 80, 2002, p. 386-400. Disponível em: <http://www.scielo.br/pdf/es/ v23n80/12938.pdf>. Acesso em: 12 jun. 2017.

LOPES, Alice Casimiro; MACEDO, Elisabeth. Planejamento. In: LOPES, Alice Casimiro; MACEDO, Elisabeth. Teorias de currículo. São Paulo: Cortez, 2011.

MACHADO, Lucas Antunes; TIMM, Jordana. Wruck; STOBÄUS, Claus Dieter. A formação de Professores de Psicologia: O Projeto Pedagógico Complementar da Licenciatura em Psicologia de uma Universidade Privada de Porto Alegre/RS. Revista Tempos e Espaços em Educação, São Cristóvão, v. 9, n. 19, p. 75-86, 2016. Disponível em: <file://C:/Users/lucas/Downloads/5597-15737-1-SM.pdf>. Acesso em: 2 jun. 2017.

MAGANO, Fernanda. Relações de trabalho do professor de Psicologia. In: CONSELHO REGIONAL DE PSICOLOGIA DE SÃO PAUlO (Org.). Ensino de Psicologia no Nível Médio: impasses e alternativas. São Paulo: CRPSP, 2010. p. 15-16.

MASSIMI, Marina. Projetos de lei prevendo a inserção da Psicologia nos currículos do ensino superior e secundário no Brasil do século XIX. Revista Psicologia: Teoria e Pesquisa, v. 9, n. 2, p. 261-269, 1993. Disponível em: <file:///C:/Users/12205065/Downloads/15879390-1-PB.pdf>. Acesso em: 26 set. 2016.

MRECH, Leny Magalhães. Casa de ferreiro, espeto de pau: o campo da Psicologia no ensino médio. In: SEVERINO, A. J.; FAZENDA, I. C. A. (Org.). Conhecimento, pesquisa e educação. Campinas, SP: Papirus, 2001. p. 143-160.

NAGLE, Jorge. Educação e sociedade na Primeira República. São Paulo: EPU, Edusp, 1974.

PANDITA-PEREIRA, Angelina. Reflexões sobre o ensino de psicologia em Escolas Técnicas Estaduais de São Paulo. Dissertação (Mestrado) - Programa de Pós-graduação em Psicologia Escolar e do Desenvolvimento Humano. 2011.

PANDITA-PEREIRA, Angelina. A constituição de motivos para as atividades escolares em jovens estudantes do Ensino Técnico integrado ao Ensino Médio. Tese (Doutorado) - Programa de Pós-graduação em Psicologia Escolar e do Desenvolvimento Humano. 2016.

PATTO, Maria Helena Souza. Psicologia e ideologia: uma introdução crítica à psicologia escolar. São Paulo: T. A. Queiroz Editor, 1984.

PATTO, Maria Helena Souza. A produção do fracasso escolar: histórias de submissão e rebeldia. São Paulo: Intermeios, 2015.

PFROMM NETTO, Samuel. As origens e o desenvolvimento da Psicologia Escolar. In: WECHSLER, S. M. (Org.). Psicologia Escolar: pesquisa, formação e prática. Campinas: Alínea, 2001.

PIAGET, Jean. Psicologia e Pedagogia. Rio de Janeiro: Forense, 1970.

RAMOS, Marise Nogueira. É possível uma pedagogia das competências contra-hegemônica?: relações entre pedagogia das competências, construtivismo e neopragmatismo. Trabalho, Educação e Saúde, v. 1, n. 1, p. 93-114, 2003. Disponível em: <http://dx.doi.org/10.1590/ S1981-77462003000100008>. Acesso em: 13 jun. 2017.

SÃO PAULO. Resolução SE no 92, de 19 de dezembro de 2007. Diretrizes para a Organização Curricular do Ensino Fundamental e Médio nas Escolas Estaduais. Secretaria da Educação. Disponível em: <http://cenp.edunet.sp.gov.br/Portal/ensino/resolucao_se_92_ ef.pdf>. Acesso em 13 jun. 2017. 
SILVA, Rosane Gumiero Dias da. Relato de uma pesquisa avaliativa sobre as contribuições da Psicologia para o ensino médio. Psicologia Ensino \& Formação, v. 2, n. 1, p. 57-76, 2010. Disponível em: <http://pepsic.bvsalud.org/pdf/pef/v2n1/06.pdf>. Acesso em: 13 jun. 2017.

SOUZA, Marilene Proença Rebello de. Política educacional e Psicologia. In: CONSELHO REGIONAL DE PSICOLOGIA DE SÃO PAUlO (Org.). Ensino de Psicologia no Nível Médio: impasses e alternativas. São Paulo: CRPSP, 2010. p. $17-21$.

SOLIGO, Ângela. Psicologia no Ensino Médio: reflexões em torno da formação. In: Conselho Regional de Psicologia de São Paulo (Org.). Ensino de Psicologia no Nível Médio: impasses e alternativas. São Paulo: CRPSP, 2010. p. 9-12.

SOLIGO, Ângela; AZZI, Roberta. Psicologia no Ensino Médio. Em defesa da Psicologia no Ensino Médio. In: ANACHE, Alexandra Ayache; RIBEMBOIM, Clara Goldman; SILVA, Iolete Ribeiro da (Org.). Seminário Nacional do Ano da Educação - Psicologia: profissão na construção da educação para todos. Brasília: Conselho Federal de Psicologia e Conselhos Regionais de Psicologia, 2009. p. 56-64.

SOLIGO, Ângela Fátima; AZZI, Roberta. Psicologia no ensino médio: desafios e perspectivas. São Paulo: Conselho Regional de Psicologia, 2008. Disponível em: <http://www.abrapee.psc.br/documentos/Texto_Base_Eixo_4_Ensino_Medio.pdf>. Acesso em: 26 set. 2016.

VASCONCELOS, J. Qualificação para o trabalho no ensino de 2º grau. Revista Brasileira de Estudos Pedagógicos, v. 57, n. 125, p. 120-143, 1972.

VALENTIM, Renata Patrícia Forain de; PEREIRA, Bárbara Albuquerque; LEITE, Rafael Felipe Pires. A Psicologia nos Programas da Escola Normal do Distrito Federal e sua adesão aos projetos eugênicos e higiênicos da Primeira República brasileira. Revista Brasileira de História da Educação, Maringá, v. 16, n. 1, p. 133-154, 2016. Disponível em: <http://www.rbhe.sbhe.org.br/index.php/rbhe/article/ view/646>. Acesso em: 21 jun. 2017.

WILLIAMS, Raymond. Cultura e materialismo. São Paulo: Editora Unesp, 2011.

Recebido em: julho/2017

Aceito em: abril/2018

\section{Endereço para correspondência:}

Lineu Norio Kohatsu <lineubr@gmail.com>

Av. Prof. Mello Moraes, 1721, Bloco A, Sala 174 - Cidade Universitária

05508-030, São Paulo, SP, Brasil 